\title{
A Standard Pediatric Dental Clinic
}

\author{
Mohammad Karimi, D.M.D and B.S* \\ Department of Pediatric, Apple Dental Clinic, Iran
}

Received: 眥July 17, 2018; Published: 畊July 25, 2018

*Corresponding author: Karimi Mohammad, D.M.D., B.S Internal Auditor \& Documentations at Apple Dental Clinic, Iran

\section{Opinion}

After 22 years of experience in pediatric dentistry, as well as working in various pediatric clinics and collecting materials over the years a standard pediatric dentistry clinic can be designed and launched. Therefore, a standard design and decoration of a clinic will have a significant impact on the success of the clinic.

Dentistry decoration is very important and influential in the morale of patients, especially in children; and it should be designed in such a way to give patients a sense of relaxation and comfort. In order to be successful in designing a dental office environment, you need to know enough about the science of color and lighting design and the correct layout of the necessary equipment in the office space, so you can design a stylish and functional decor for dentistry, especially for children. In the design of the interior decoration of the office, you have to master the internal and external environment of the building, the principles of lighting, and the proper layout of medical equipment, so that you can make the right design using the correct and integrated design.

Remember to use the rules of the architecture of the day in the world as much as possible to design interior decoration so that with the help of these sciences and laws you can design a clinic that is very special and relaxing. Choose the effects of colors in terms of color and design that make patients feel more comfortable. Nowadays, dentists use a lot of ways to attract customers. One of them is to put a staff member to advertise their work and explain the services and benefits they offer as well as someone who invites you to visit different parts of the clinic like a tour to explain the various functions of each space. Many modern dental clinics are equipped with amusement and recreational facilities, specially designed children's reception areas and even relaxation spaces. Adaptive space design elements such as ceiling height, doors, woodwork s, lighting, and painting must all be carefully designed to create a favorable atmosphere for referrals patients.

\section{Clinic Spaces}

Have you ever thought that what kind of spaces should be used by a standard dental clinic? In other words, what specific rooms do you have in your clinic? Generally, each pediatric dental clinic should be equipped with eleven completely separate spaces.
a) Receptions area and File archive
b) Waiting room for parents
c) Management room
d) Play room
e) Dentist's private office
f) Examination room
g) Treatment room
h) Radiography room
i) Central Sterilization center
j) Dental lab
k) Supporting department

\section{Reception area}

The admission section is the first space that visitors enter, so it can be of great importance to design. Because patients will judge and view details of the entire project when they enter the reception area. Therefore, the design of this space should be such that it attracts them. In general, the admission section should convey the sense of inviting and welcoming. For the office clerk, who is responsible for accepting patients and archiving file an appropriate place must be considered for her. The admissions section should be such that the patients sit on one side and the office staffs stay on the other side. At the same time, visitors can talk to the staff at the reception desk and fill in the necessary forms.

\section{Waiting room for parents}

The second part should be considered for patients who come to the dentist's office. Pediatric patients are better off staying in their waiting room before the treatment begins. Many modern dental clinics are equipped with a laptop and mobile phone charging stations at the coffee shop, which they can take advantage of these during their children's treatment. Some clinics also have foot massage devices, as well as a place to show new oral and dental products, all of which are an example of this new facility. 
In some clinics, there is a special area to use for the aquarium. The installation of a special shelf for a variety of magazines and books can give parents entertainment. It is better to have separate bathrooms for children and adults in the corner of the hall.

\section{Management room}

In the design of the management room, the goals are determined by types of decorations and designs. The management room should represent the personality, authority, ability of a good manager. In fact, this decoration tells the patient that the manager has his own rules. When entering the room, the patient must understand that it can be trusted by the manager, regardless of the type of contact, the appearance of the manager, the arrangement of the furniture and any details about it.

In addition to the type of office arrangement, one should also be sensitive to the colors used. Never use fancy colors for interior design. Colors with a cream range and a combination of cream colors with white and light brown are the most suitable colors for the interior design of office chairs. The interior lighting of the room is also very important. It's better to use modern lighting to make the management room decorations more attractive.

\section{Play room}

When designing a dental clinic for children, by installing posters of popular children's characters on the wall or putting toys in the waiting room, you would encourage them to come to the clinic. If your clinic has a great deal of space, with a number of small play tables, you can create an environment where children can draw and play together. The use of creative children's designs and bright and cheerful colors in the interior decoration of the dentistry takes the child's mind out of the atmosphere of the dental space. For the kid's waiting room, you can use children's cartoon images and characters, in the form of posters on the walls; or have a shelf of full of toys to play. In this environment, children will be away from the noisy environment and adults' complaints; and they will be more comfortable with their peers in the room, with no fears and concerns. Installing DVDs or TVs to play animations is another important thing that can entertain children. If the waiting room is large enough, considering a playground is a very interesting and tempting idea to attract children.

\section{Dentist's private office}

The private office is becoming increasingly important in design with the belief that it is important for the dentist to have "private" areas to rest there during the day for mental breaks. It is better to have a comfortable sofa, or even beyond that a recliner chair equipped with a massage device in the room so that remove fatigue from the dentist's body. Large windows always give e sense of peaceful atmosphere and make the psychological break more relaxed and smooth. Consider a private closet and bathroom to accompany the office.

\section{Examination room}

It is designed for initial patient examinations. Of course, in most clinics, this room has been integrated into the treatment room due to lack of space. But for a pediatric dental clinic, the separation of such a room is essential for children, because for the initial examination it is not necessary for the child to go to the treatment room and have too much anxiety. It should be noted that this is the first place a child gets familiar with the dentist. In addition, this room should create a feeling of a happiness and childish atmosphere in the child. In the examination room, we have to try to create a stressfree space where the child would feel more comfortable. A dental environment should be a happy and comfortable place for children. Therefore, the principle design of this room is very important for the initial impact on the child.

The examination room and treatment room to some extent in terms of instrumental layout and decoration arrangement should be different. Having options such as colored dresses or dresses with children's favorite cartoon characters, masks and colored gloves in this room, will have an impressive effect. It would be more impressive if pediatric dental chairs are characterized by different special childish designs.

The walls of the examination room should be in bright colors and decorated with special posters for kids. Near the dental chair, there should be oral hygiene kits including baby doll toothbrush, children's toothpaste, and a dent form. On the dental chair, devices such as kid's dental turbines, kid's handpieces with a rubber tip on it, and small monitors to be installed. By doing this strategy, you can prepare a good background for children to familiar with the environment and some of the dental instruments.

\section{Treatment room}

The next space includes the patient treatment ward. The dental chair in the treatment room is a device that the patient undergoes for the duration of the treatment while at the same time tolerates dental panic and anxiety. A dental unit with a variety of instruments, such as the turbine, handpieces, suction, lamp, etc. may be daunting for children who are going to the dental office for the first time. For a pediatric dental clinic, this room is one of the most important parts of the clinic. This room is a place where the child should not get anxious and stressed when arriving. Therefore, it must be designed and installed in such a way that the patient feels calm and comfortable. The atmosphere inside the treatment room should be cheerful and childish. Dental units with pediatric designs should be replaced by the conventional units. The color of the room and the units should be cheerful and relaxing. In the decoration and design of this room, there must be a special creativity that upon the arrival, the child does not have the feeling to be taken to the dentist's office.

Instead, he will have the feeling that he has entered into a friendly and childish environment or imaginary space. To reduce 
the stress on children, place a dental chair in front of your office window. You can bring mental relaxation to your treatment room if you follow these principles:

1) If the office room is on the ground floor and adjacent to the courtyard, you can use full-glass windows: and plant all kinds of greens and flowers in the garden opposite these windows.

2) If the room is on the floor of a building with its window opening to the leaves of the trees, you can give a Stunning and tranquil view to patient's eyes on the dental unit.

3) But in some cases, your office may be in the basement of a building and the room where the unit is to be installed does not have a window; in this case, you can hang a beautiful, relaxing painting in front of the dental chair.

You can even have an aquarium with different fish in front of your unit. Various studies have shown that water and slow motion of fish can be effective in reducing anxiety and stress in patients. As another step, you can put headphones on your unit for the patient, and play light and relaxed music; or, let the children's music spread through the speakers with a gentle tone of voice. Sometimes the installation of a television in front of the unit can also be effective because the patient's mind focuses on other programs and images. And their minds divert the issue of pain and fear from the dental environment to other issues.

\section{Radiography room}

Regardless on which wall the x-ray machines are placed, make sure that the equipment and chair are positioned to allow ease of access to both left and right sides of the mouth. Many offices plan for a panographic radiographic machine even if they do not currently have one. The installation of a suitable air suction device in the radiographic room is mandatory. The radiograph door must have a lead of 2 millimeters and be fitted with appropriate grips and hinges for the door. Today, many dental offices make use of digital radiography.

\section{Central sterilization room (CSR)}

To control the infection, this is the area that provides the facilities for washing the clothes in the same environment so that employees do not have to carry clothes with them to wash them home or out of the health environment. This is also a special room to sterilize all instruments used daily. This section includes a washing room, an ultrasonic machine, an oil machine, a pack unit, an autoclave unit and other necessary pieces of equipment.

\section{Dental laboratory}

You can design the lab outside the range and in the hallway or separate it with one in the treatment room. If a laboratory space is included in the clinic design, it is better to place this room at the very end of the clinic space away from the treatment room and playroom. This will reduce the sound emission from the lab, which is a factor in exacerbating stress in children and parents. Some dentists prefer to use a lab in the city.

\section{Supporting department}

The final part of the clinic space is including a staff break room, a changing room, a small kitchen for staffs and a warehouse of materials and equipment.

\section{Tips for choosing color and light for a dental clinic}

Can you imagine the world around you without any color? Each color has a special physical and emotional effect on the viewer, and people have different reactions to different colors. Color, light, and water can help you create a clear and vivid environment in the office. First of all, you have to pay attention to what color you are interested in? Do you prefer to use gentle colors for walls and units or use energy colors that inspire a happy mood in you and your patients?

Undoubtedly, the use of happy colors is very important for designing the baby's waiting room. In choosing your color scheme, you need to be careful about matching colors. The use of bright colors like light blue or cream makes the office space wider. The use of mirrors can also help to make the office larger. Mild colors can also affect the patient's inner peace.

You can also use a colorful background for the waiting room and the treatment room, and only consider the degree of darkness and brightness of the color in these two rooms. It is better to use the same color for the waiting room and the treatment room. In this situation, patients who got familiar with the reception room before entering the treatment room will get familiar with the new environment without any stress.

Avoid using absolute white or yellow light, to create a light like daylight by combining these two colors by installing suitable lamps. Choosing the tooth color for all types of composites and ceramics is easier and more accurate in these light conditions. Also, the use of natural herbs brings a refreshing effect to your clinic and helps to stimulate relaxation. Colors that are commonly used in the design of the clinic environment are bright colors. White is at the top of these colors and is almost the first color that reminds you of a Treatment room. The use of white color in this space cannot be simply attributed to its conventionality. The white color is a color that reflects the light well, while at the same time special beauty. This color is also very effective in making people feel relaxed. So, the white will be the first color to be offered in the decoration design of the clinic. 
(C) Comons Attribution 4.0 License

To Submit Your Article Click Here: Submit Article

DOI: 10.32474/MADOHC.2018.03.000152

\section{Modern Approaches in Dentistry and Oral Health Care}

MADOHC

\section{Assets of Publishing with us}

- Global archiving of articles

- Immediate, unrestricted online access

- Rigorous Peer Review Process

- Authors Retain Copyrights

- Unique DOI for all articles 